\title{
Quality of Life among Iranian Postmenopausal Women: A Systematic Review and Meta-Analysis
}

\author{
Khadijeh Sharifi ${ }^{1}$, Zahra Tagharrobi ${ }^{1}$, Zahra Sooki ${ }^{1 凶}$
}

${ }^{1}$ Trauma Nursing Research Centre, Faculty of Nursing and Midwifery, Kashan University of Medical Sciences, Kashan, Iran

\begin{abstract}
Menopause can cause mental, physical, vasomotor, and sexual symptoms and problems, which negatively affect the quality of life (QOL). The aim of this study was to systematically evaluate QOL among Iranian postmenopausal women. This systematic review was conducted on cross-sectional studies that were published between 2000 and 2018. An online search to find studies published in English or Persian was conducted in the databases of Web of Science, PubMed, ScienceDirect, Scopus, Google Scholar, Scientific Information Database, Magiran, and IranMedex. Search key terms were "quality of life", "menopause", and "Iran". Fourteen studies were eligible for this study. The Strengthening the Reporting of Observational Studies in Epidemiology (STROBE) checklist was used for quality appraisal. The mean and standard deviation of QOL and its domains were extracted from the selected studies. Study data were analyzed using the Review Manager (v. 5.0) and the STATA (v. 12.0) software. The mean of total QOL among 3413 postmenopausal women was $57.89 \pm 12.8$ (in the possible range of $0-174$ ). The means of its vasomotor, psychosocial, physical, and sexual domains were $7.86 \pm 2.14$, $19.43 \pm 2.05,40.58 \pm 3.33$, and $6.71 \pm 1.77$, respectively. The QOL among Iranian postmenopausal women is nearly higher than the moderate level. The lowest and the highest levels of QOL are related to the physical and sexual domains, respectively. Health authorities need to develop educational interventions to promote postmenopausal women's QOL, particularly in the physical domain. [GMJ.2020;9:e1649] DOI:10.31661/gmj.v9i0.1649
\end{abstract}

Keywords: Menopause; Quality of Life; Systematic Review; Meta-Analysis

\section{Introduction}

$\mathrm{A}$ s a physiological phenomenon, menopause is the termination of menstruation and reproduction. It is among the most important phases of women's life [1]. Life expectancy improvement in recent years has significantly increased the number of postmenopausal women [2]. Currently, women spend around one third of their lives after

\section{GMJ}

Copyright $($ 2020, Galen Medical Journal. This is an open-access article distributed under the terms of the Creative Commons Attribution 4.0 International License (http://creativecommons.org/licenses/by/4.0/) Email:info@gmj.ir menopause and hence, postmenopausal period has received special attention during recent years. Menopause is associated with different physiological changes and problems such as hot flashes, nighttime sweating, anxiety, headache, fatigue, irritability, and sleep disorders $[3,4]$. Thereby, it can significantly affect quality of life (QOL) [1, 4,5]. According to the World Health Organization, QOL is "an individual's perception of their position in life in

\footnotetext{
Correspondence to:

Zahra Sooki, Trauma Nursing Research Centre, Faculty of Nursing and Midwifery, Kashan University of Medical Sciences, Ravand Street, Kashan, IR Iran Telephone Number: +989121461374

Email Address: Sooki_za@kaums.ac.ir
} 
the context of the culture and value systems in which they live and in relation to their goals, expectations, standards, and concerns" $[6,7]$. QOL includes different vasomotor, sexual, physical, and mental aspects and its improvement is among the goals of the health for all programs[8]. Different studies reported the negative effects of menopause on QOL [5, 9-13]. For instance, a study reported significant correlations between menopausal symptoms and different aspects of QOL and concluded that the climacteric period can have negative effects on the physical and mental aspects of QOL [10]. Another study also found that postmenopausal women had poor QOL [14]. Progression of menopause was also reported to reduce QOL, so that older postmenopausal women had lower QOL [15]. Contrarily, some studies reported the non-significant effects of menopause on QOL $[16,17]$ and the non-significant correlations of menopausal symptoms with QOL [17-20]. A review study also reported that there is no clear pattern for the relationship between menopause and the mental aspect of QOL [20]. QOL measurement could provide valuable data about patients' feelings, problems, and needs and also about the effects of preventive and health-promoting measures and programs[13].However, previous studies reported varying levels of QOL among menopausal women $[4,5,9-13]$ and hence, there is no conclusive evidence about their QOL status. To fill this gap, this study was conducted. The aim of the study was to systematically evaluate QOL among Iranian postmenopausal women.

\section{Search Strategy}

As a systematic review and meta-analysis, this study was conducted in 2018 on studies into QOL among Iranian postmenopausal women. An online search was performed in national and international scientific databases such as Web of Science, PubMed, ScienceDirect, Scopus, Google Scholar, Scientific Information Database, Magiran, and Iranmedex. Search key terms were "quality of life", "life quality", "health-related quality of life", "HRQOL", "menopause", and "Iran"as well as their equivalents in the Medical Subject Headings. Boolean operators "AND" and
"OR" were also used to combine search results. Since some Iranian databases showed no sensitivity to search operators (AND, OR), the search in the Iranian database was done by main, sensitive, and public keywords such as "menopause" and "quality of life" to provide a high sensitivity.

\section{Study Selection}

Study selection was independently done by two of the authors(Z.S. and Kh.Sh.) and their disagreements were resolved by a third author (Z.T.). In the first step of theonline search, 624 records were retrieved. Similar records were excluded and 206 records were kept. In the second step, irrelevant studies were excluded and 88 studies which were in some ways relevant to menopausal women's QOL were extracted. In the third step, all these 88 studies and their references were assessed for eligibilityand finally, 14 eligible studies were selected for meta-analysis (Figure-1). Eligibility criteria were publication in Persian or English between 2000 to July 2018, cross-sectional descriptive design, and QOL assessment among postmenopausal women using the Menopause-specific Quality of Life (MenQOL) questionnaire. Any ambiguities in the selected studies were clarified throughcontacting their authors viaemail or telephone. The EndNote software (v. X7, Thomson Reuters EndNote) was used to save and manage the studies. The 29-item MenQOLassesses postmenopausal women's QOL in four main domains, namely vasomotor (3 items), psychosocial (7 items), physical (16 items), and sexual (3 items). Its items are scored from 0 ("Lowest severity") to 6 ("Highest severity"). Therefore, the total score of the questionnaire and its vasomotor, psychosocial, physical, and sexual domains can range from 0 to respectively $174,18,42$, 96, and 18. Higher scores show lower QOL and vice versa. The scoring of MenQOL items in the selected studies had been performed on either a $0-5$ or $0-6$ scale[21]. In the present study, the results reported in the retrieved studies were changed into a 0-6 scale.

\section{Quality Appraisal}

Quality appraisal was performed using the Strengthening The Reporting of Observation- 
al Studies in Epidemiology (STROBE) checklist. The seven main criteria assessed using this checklist were; detailed explanation of the purpose, accurate description of the place and the time of the study, inclusion criteria and selection procedures, adequacy of sample size, ethical considerations, statistical analysis, and control of lost samples. Each of the criteria has scored; high 0 , unclear 1 and low risk of bias 2.The more score, the lower risk (Table-1 and Figure-2).

\section{Data Analysis}

Study data were analyzed at a significance level of less than 0.05 using the Review Manager (v. 5.0, Cochrane community, London, UK) and the STATA (v. 12.0, Stata Corp, College Station, TX, USA) software. Heterogeneity was tested through the Q test and the I2statistic [22]. Meta-analysis was performed through the randomeffects model for sexual domain (because of high heterogeneity) and for other variables the fixed effects model (because of nothing heterogeneity, Figures-3 and 4). The Tau squared value was also used to assess the variance among the studies[23] and publication bias was assessed through Egger's test. The means and standard deviations of QOL and its four domains were extracted from each study and then, were combined proportional to the sample size of each study using the fixed effects model.

\section{Results}

The total number of postmenopausal women in the fourteen reviewed studies was 6293. The mean of their age was $54.33 \pm 2.58$. Table-2 shows the characteristics of the reviewed studies. The Egger's test showed that there was no publication bias (Figures-5 and $6)$. The mean of total QOL had been reported only in ten studies with a total sample size of 3413. The mean of total QOL in these ten
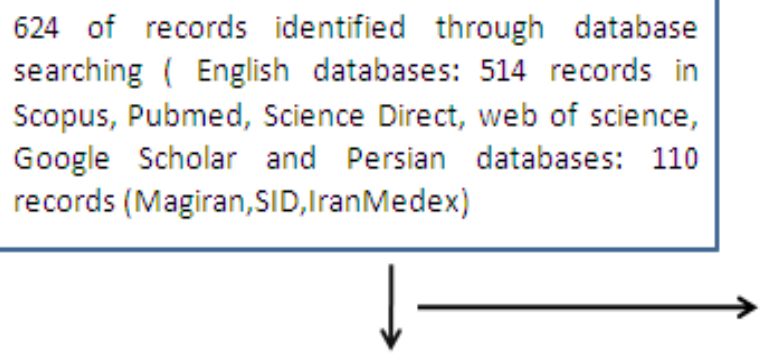

206 (127 English , 79 Persian)

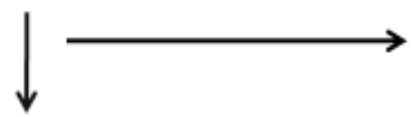

88 (59 English , 29 Persian) of full-text articles assessed to eligibility, including their references

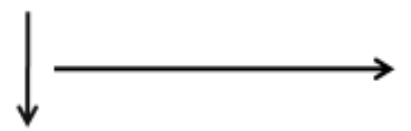

14 of studies ( 6 articles in English and 8 articles in Persian) included in quantitative synthesis (meta-analysis)
Removing duplicated ones (387 English and 31 Persian)
Not relevant (118 of records excluded after review of title and abstract, 68 English, 50 Persian)
Not relevant or no adequate data (74 of records excluded after review of full-text ,53 English, 21 Persian)

Figure 1. The flow diagram of the study 


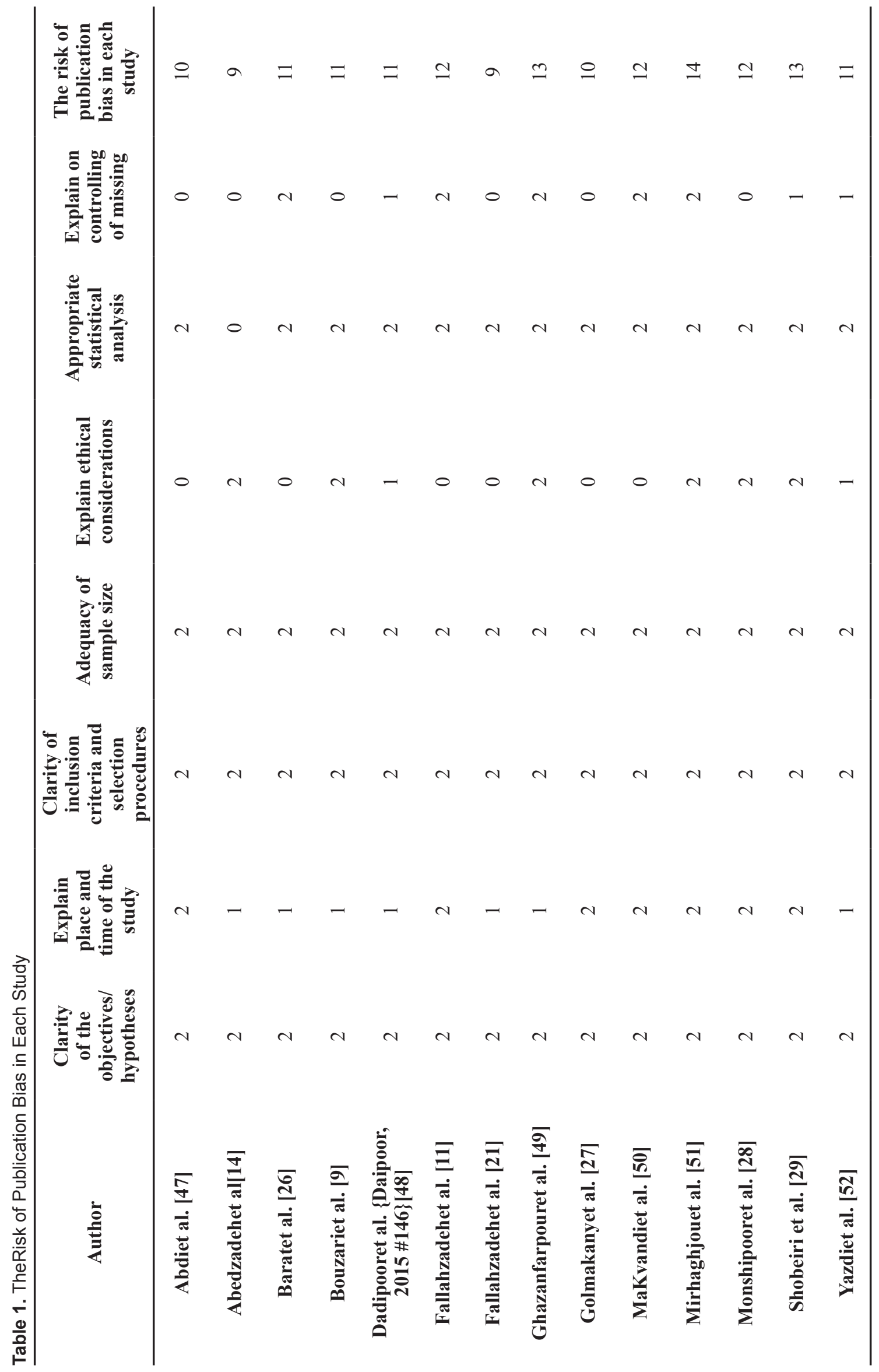




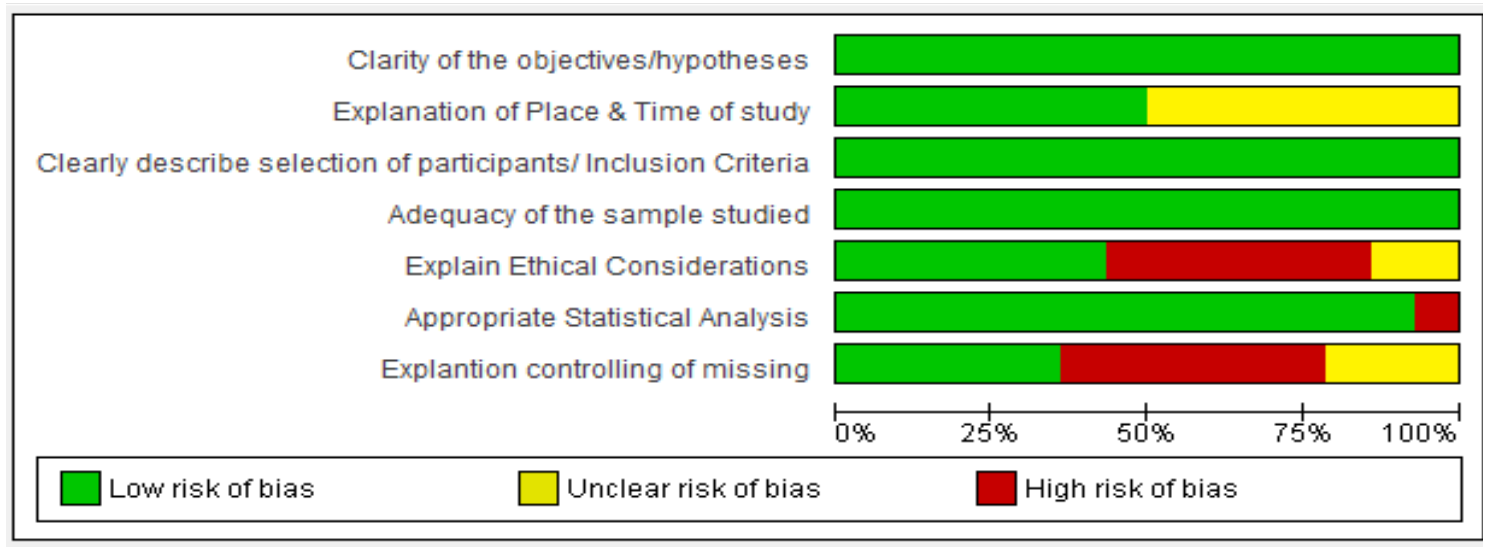

Figure 2. The total risk of publication bias

\begin{tabular}{|c|c|c|c|c|c|c|c|}
\hline \multirow{2}{*}{$\begin{array}{l}\text { Study or Subgroup } \\
\text { Abdi. N(2014) }\end{array}$} & Mean of Total Quality of life & SE & Total & \multicolumn{2}{|r|}{ Mean of Total Quality of life } & \multicolumn{2}{|c|}{$\begin{array}{c}\text { Mean of Total Quality of life } \\
\text { IV, Fixed, } 95 \% \mathrm{Cl}\end{array}$} \\
\hline & 43.28 & 35.52 & 700 & & Not estimable & & \\
\hline Abedzadeh.M (2009) & 84.99 & 28.7 & 700 & $5.2 \%$ & $84.99[28.74,141.24]$ & & \\
\hline Dadipoor.S(2015) & 76.62 & 27.05 & 170 & $5.8 \%$ & $76.62[23.60,129.64]$ & & \\
\hline Fallahzadeh.H(2011) & 38.1 & 12.9 & 300 & $25.6 \%$ & $38.10[12.82,63.38]$ & & $\longrightarrow$ \\
\hline Ghazanfarpour.M(2013) & 61.38 & 28.39 & 233 & $5.3 \%$ & $61.38[5.74,117.02]$ & & \\
\hline Golmakany.A(2014) & 84.28 & 29 & 375 & $5.1 \%$ & $84.28[27.44,141.12]$ & & \\
\hline Makvandi.S(2013) & 84.39 & 28.48 & 400 & $5.2 \%$ & $84.39[28.57,140.21]$ & & \\
\hline Mirhaghjou.SN(2015) & 52.49 & 50.46 & 675 & $1.7 \%$ & $52.49[-46.41,151.39]$ & & \\
\hline Monshipour.SM(2014) & 58.25 & 11 & 180 & $35.1 \%$ & $58.25[36.69,79.81]$ & & \\
\hline Yazdi.Z(2013) & 54.5 & 19.6 & 380 & $11.1 \%$ & $54.50[16.08,92.92]$ & & \\
\hline Total $(95 \% \mathrm{Cl})$ & & & 3413 & $100.0 \%$ & $57.89[45.11,70.67]$ & & \\
\hline $\begin{array}{l}\text { Heterogeneity: } \mathrm{Chi}^{2}=5.4 \\
\text { Test for overall effect: } Z=\end{array}$ & $\begin{array}{l}d f=8(P=0.71) ; 1^{2}=0 \% \\
88(P<0.00001)\end{array}$ & & & & & $\frac{1}{-50}-25$ & 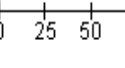 \\
\hline
\end{tabular}

Figure 3. The mean score of total QOL in each study based on the results of the fixed-effects model

studies was calculated to be $57.89(95 \%$ confidence interval: 45.11-70.67). Figures-3 and 4 show the total mean scores of QOL and its different domains, respectively. The lowest total mean score of QOL among the reviewed studies was 38.1 (95\% confidence interval [95\%CI] 12.82-63.38) [21], while the highest total mean score of QOL was 84.99 (95\% CI: 28.74-141.24)[14].

\section{Discussion}

This study aimed to estimate QOL among Iranian postmenopausal women. In total, fourteen studies were reviewed. However, the total number of studies analyzed in meta-analysis varied for each of MenQOLdomains. Accordingly, the number of the analyzed studies was ten for the vasomotor and the sexual domains, eleven for the psychological and the physical domains, and ten for total QOL. The mean score of the vasomotor domain of QOL was 7.86 \pm 2.14 (in the possible range of $0-18$ ), which is almost at moderate level. This value was $9.6 \pm 6.6$ in a cross-sectional study on 2703 American postmenopausal women [13], 5.49 \pm 4.74 in a study on 770 Iranian premenopausal women aged $45-60$ [24], and 8.88 \pm 8.82 in a cross-sectional study on 100 Indian postmenopausal women [25]. The difference among these studies respecting the mean score of the vasomotor domain of QOL can be attributed to the fact that QOL is affected by factors such as age [10, 26-28], ethnicity, sociocultural environment, lifestyle [13, 15], educational level, employment, income, physical activity, and access to reliable information services for receiving counseling and information about coping with menopause $[29,30]$. The mean score of QOL in the psychosocial domain was $19.43 \pm 2.05$ (in the possible range of $0-42$ ). 


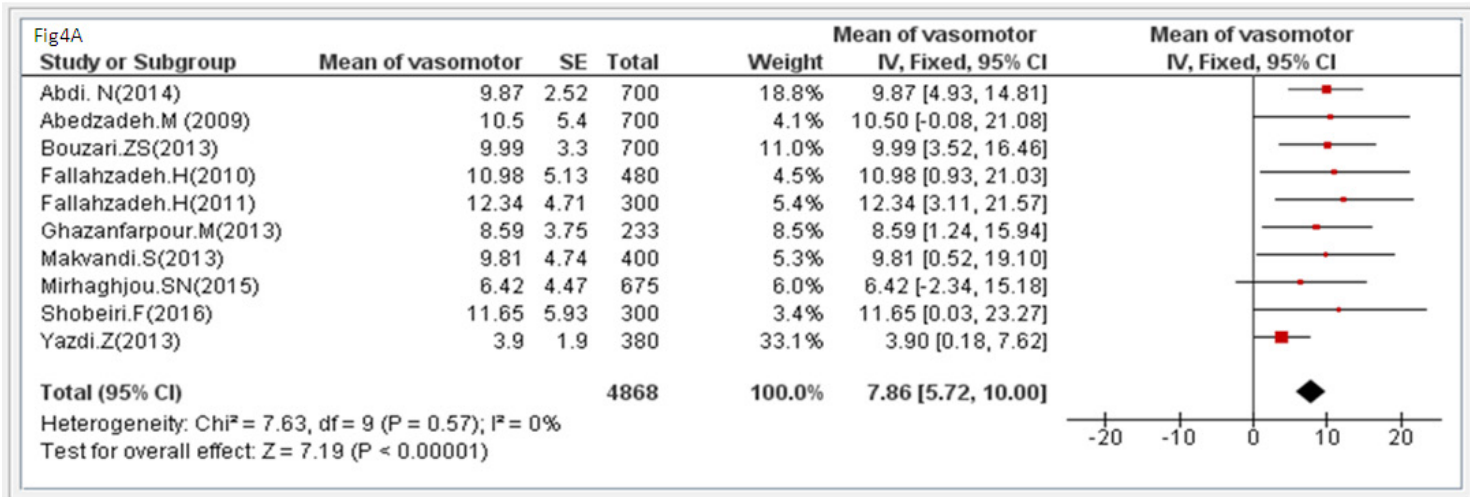

\begin{tabular}{|c|c|c|c|c|c|c|c|c|c|c|}
\hline $\begin{array}{l}\text { Fig4B } \\
\text { Study or Subgroup }\end{array}$ & Mean of psychological & SE & Total & \multicolumn{2}{|r|}{ Mean of psychological } & \multicolumn{5}{|c|}{$\begin{array}{c}\text { Mean of psychological } \\
\text { IV, Fixed, } 95 \% \mathrm{Cl}\end{array}$} \\
\hline Abdi. N(2014) & 21.14 & 3.84 & 700 & $7.4 \%$ & $21.14[13.61,28.67]$ & & & & $\rightarrow$ & \\
\hline Abedzadeh.M (2009) & 21.8 & 8.8 & 700 & $1.4 \%$ & $21.80[4.55,39.05]$ & & & & & \\
\hline Barat.Sh(2013) & 23.07 & 6.52 & 700 & $2.6 \%$ & $23.07[10.29,35.85]$ & & & & & \\
\hline Bouzari.ZS(2013) & 26.88 & 7.56 & 700 & $1.9 \%$ & $26.88[12.06,41.70]$ & & & & & \\
\hline Fallahzadeh.H(2010) & 20.3 & 10.36 & 480 & $1.0 \%$ & $20.30[-0.01,40.61]$ & & & & & \\
\hline Fallahzadeh.H(2011) & 18.15 & 8.89 & 300 & $1.4 \%$ & $18.15[0.73,35.57]$ & & & & & \\
\hline Ghazanfarpour.M(2013) & 17.37 & 8.79 & 233 & $1.4 \%$ & $17.37[0.14,34.60]$ & & & & & \\
\hline Makvandi.S(2013) & 19.47 & 8.48 & 400 & $1.5 \%$ & $19.47[2.85,36.09]$ & & & & & \\
\hline Mirhaghjou.SN(2015) & 10.92 & 5.95 & 675 & $3.1 \%$ & $10.92[-0.74,22.58]$ & & & & E & \\
\hline Shobeiri.F(2016) & 19.36 & 1.2 & 300 & $76.1 \%$ & $19.36[17.01,21.71]$ & & & & $\square$ & \\
\hline Yazdi.Z(2013) & 17.4 & 7.1 & 380 & $2.2 \%$ & $17.40[3.48,31.32]$ & & & & & \\
\hline Total $(95 \% \mathrm{Cl})$ & & & 5568 & $100.0 \%$ & $19.43[17.38,21.48]$ & & & & $\bullet$ & \\
\hline $\begin{array}{l}\text { Heterogeneity: } \mathrm{Chi}^{2}=3 \text {. } \\
\text { Test for overall effect: } Z\end{array}$ & $\begin{array}{l}d \mathrm{df}=10(P=0.96) ;\left.\right|^{2}=09 \\
18.57(P<0.00001)\end{array}$ & & & & & $\frac{1}{-50}$ & -25 & 0 & 25 & 50 \\
\hline
\end{tabular}

\begin{tabular}{|c|c|c|c|c|c|c|c|c|c|c|}
\hline \multirow{2}{*}{$\begin{array}{l}\text { Fig4C } \\
\text { Study or Subgroup } \\
\text { Abdi. N(2014) }\end{array}$} & Mean of physical & SE & \multirow{2}{*}{$\begin{array}{r}\text { Total } \\
700\end{array}$} & \multirow{2}{*}{$\frac{\text { Weight }}{3.3 \%}$} & \multirow{2}{*}{$\begin{array}{c}\begin{array}{c}\text { Mean of physical } \\
\text { IV, Fixed, 95\% Cl }\end{array} \\
51.13[32.92,69.34]\end{array}$} & \multicolumn{5}{|c|}{$\begin{array}{l}\text { Mean of physical } \\
\text { IV, Fixed, } 95 \% \mathrm{Cl}\end{array}$} \\
\hline & 51.13 & 9.29 & & & & & & & $\longrightarrow$ & \\
\hline Abedzadeh.M (2009) & 44.37 & 17.19 & 700 & $1.0 \%$ & $44.37[10.68,78.06]$ & & & & & \\
\hline Barat.Sh(2013) & 55.38 & 7.99 & 700 & $4.5 \%$ & $55.38[39.72,71.04]$ & & & & & \\
\hline Bouzari.ZS(2013) & 55.04 & 7.86 & 700 & $4.7 \%$ & $55.04[39.63,70.45]$ & & & & & \\
\hline Fallahzadeh.H(2010) & 39.68 & 16.6 & 480 & $1.0 \%$ & $39.68[7.14,72.22]$ & & & & & \\
\hline Fallahzadeh.H(2011) & 41.09 & 16.37 & 300 & $1.1 \%$ & $41.09[9.01,73.17]$ & & & & & \\
\hline Ghazanfarpour.M(2013) & 31.4 & 16.85 & 233 & $1.0 \%$ & $31.40[-1.63,64.43]$ & & & & & \\
\hline Makvandi.S(2013) & 43.87 & 13.87 & 400 & $1.5 \%$ & $43.87[16.69,71.05]$ & & & & & \\
\hline Mirhaghjou.SN(2015) & 30.56 & 8.32 & 675 & $4.2 \%$ & $30.56[14.25,46.87]$ & & & & - & \\
\hline Shobeiri.F(2016) & 39.12 & 1.95 & 300 & $75.7 \%$ & $39.12[35.30,42.94]$ & & & & & \\
\hline Yazdi.Z(2013) & 32.5 & 11.9 & 380 & $2.0 \%$ & $32.50[9.18,55.82]$ & & & & & \\
\hline Total $(95 \% \mathrm{CI})$ & & & 5568 & $100.0 \%$ & $40.58[37.25,43.90]$ & & & & $\bullet$ & \\
\hline \multicolumn{4}{|c|}{$\begin{array}{l}\text { Heterogeneity: } \text { Chi }^{2}=10.98, d f=10(P=0.36) ; I^{2}=9 \% \\
\text { Test for overall effect: } Z=23.92(P<0.00001)\end{array}$} & & & -100 & -50 & 0 & 50 & 100 \\
\hline
\end{tabular}

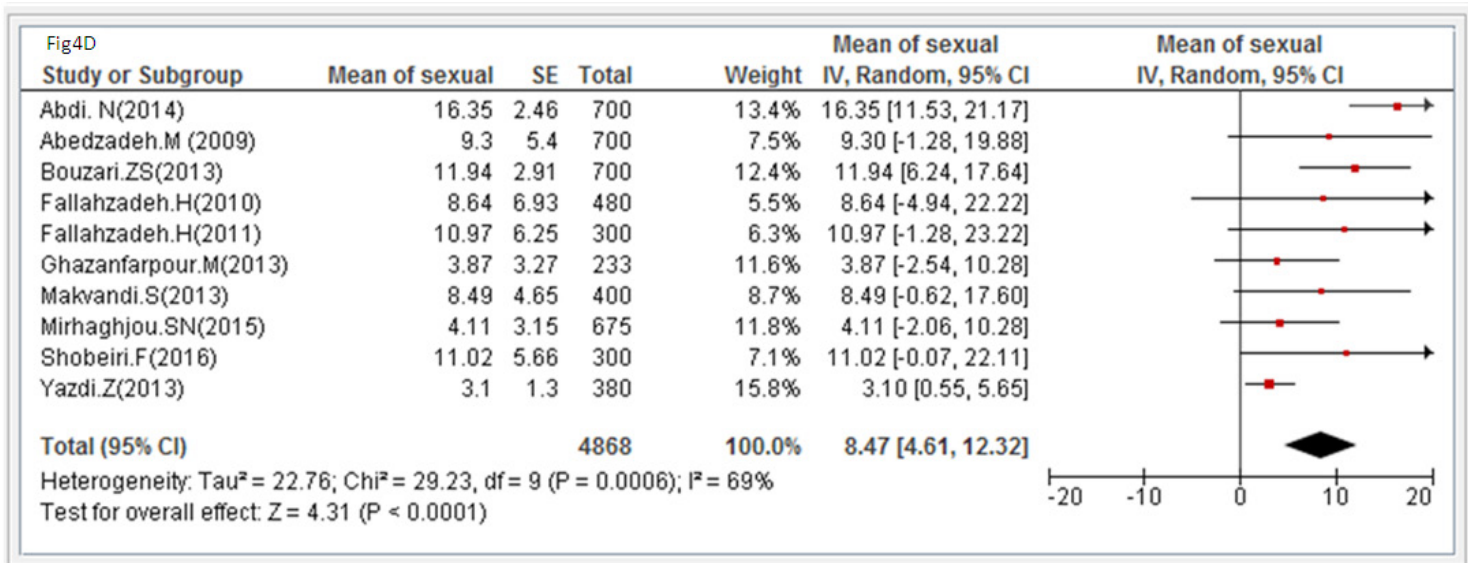

Figure 4. The mean scores of QOL domains in each study based on the results of the fixed-effects model 





This score shows moderate QOL in the psychosocial domain. This value in two previous studies was $23.1 \pm 12.6$ [13] and $26.64 \pm 17.88$ [25]. Irrespective of menopause, low QOL may be associated with mood changes and the feeling of tension [31]. In a review study by Vesco et al. (2008), nine reviewed studies had reported that menopause had no significant correlations with depression, negative mood, major depressive disorder, general mental health, and other mental symptoms, while three studies had found higher prevalence of depression among postmenopausal women and one study had reported higher well-being among postmenopausal women. That study also reported that socioeconomic status and educational level could affect the severity of menopausal symptoms and QOL [20]. Lifestyle factors such as diet, physical exercise, and social activities can affect psychosocial status and QOL [32]. Some studies on postmenopausal women in Iran also showed that women with membership and participation in social association had better QOL and positive emotionsprobably due to governmental support for these associations [33, 34]. Also, our findings revealed that the mean score of QOL in the physical domain was $40.58 \pm 3.33$ (in the possible range of $0-96$ ). This score denotes that Iranian postmenopausal women's QOL in the physical domain was better than the moderate level. This value in two earlier studies was $56 \pm 24$ [13] and $63.54 \pm 35.34$ [25]. A review study showed that premenopausal period is associated with high levels of physical symptoms [35]. A cross-sectional study on 410 postmenopausal women in Turkey also indicated that they had experienced physical symptoms more frequently than the symptoms in other domains of QOL [36], while a study reported lower physical QOL at the beginning of menopause[15]. Another cross-sectional study in Malaysia on 258 Malay, Indian, and Chinese postmenopausal women showed that Asian women had mostly experiencedmenopause-related musculoskeletal symptoms, while western women had mostly experienced vasomotor symptoms. These findings imply the effects of ethnicity on menopausal symptoms. Of course, that

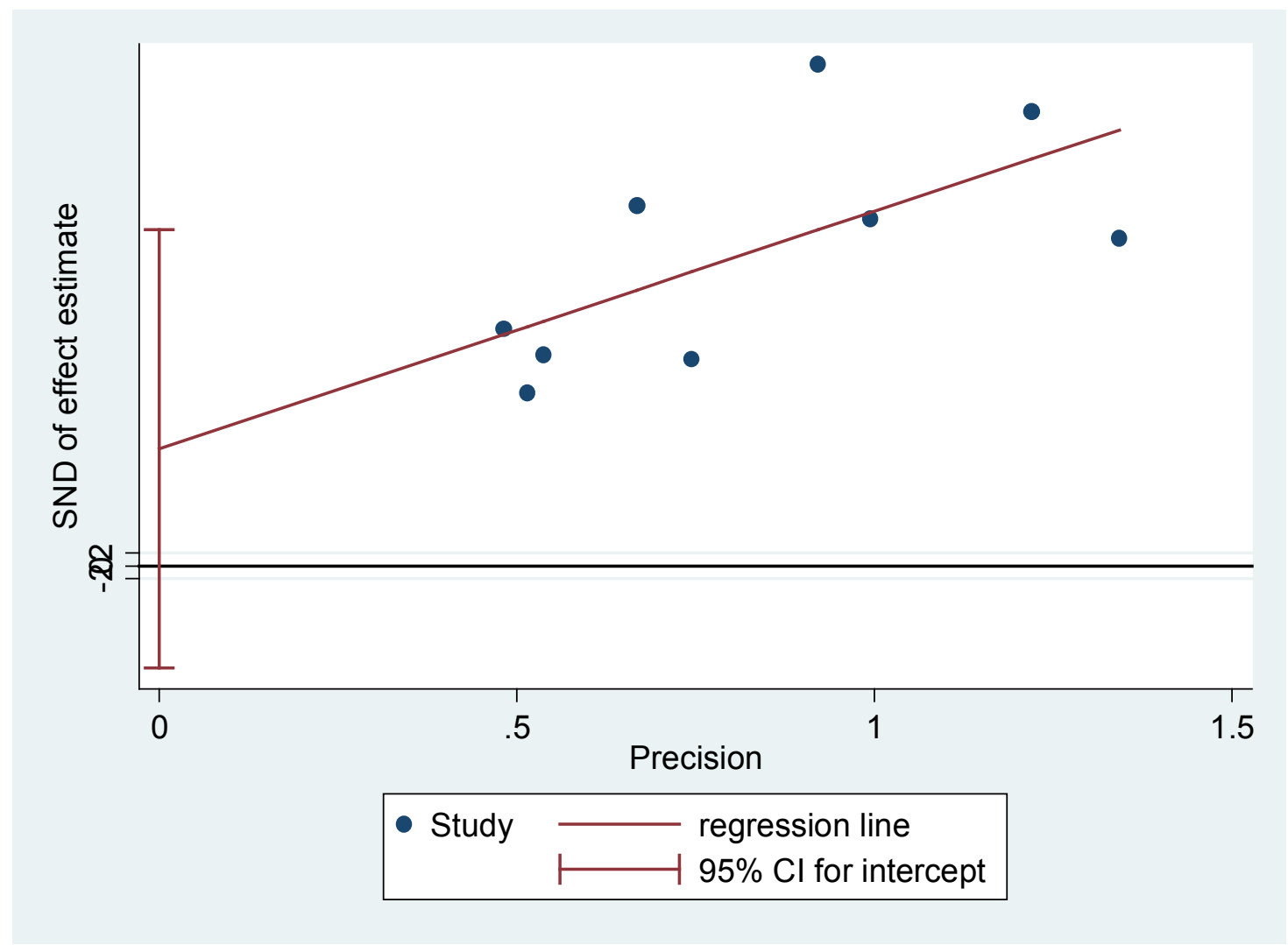

Figure 5.The Egger test for publication bias (total quality of life), $P=0.247$ 
A

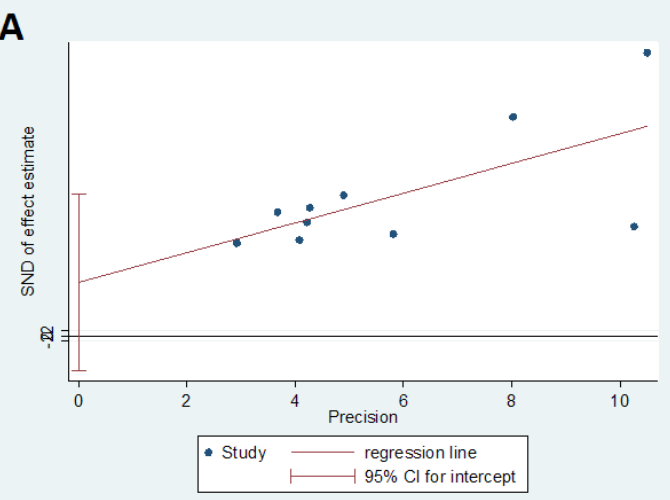

B

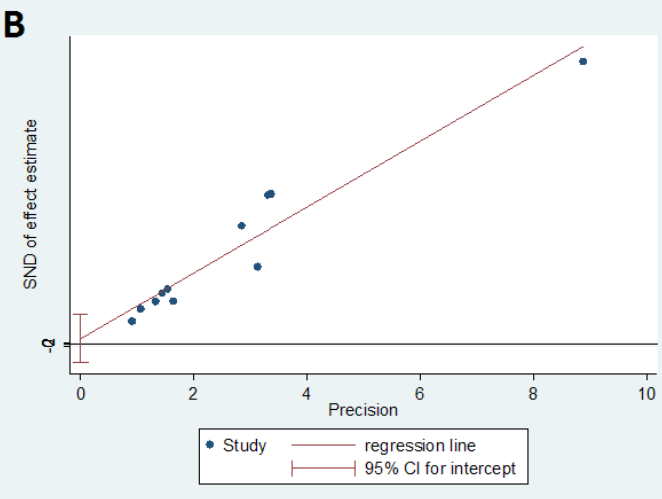

C

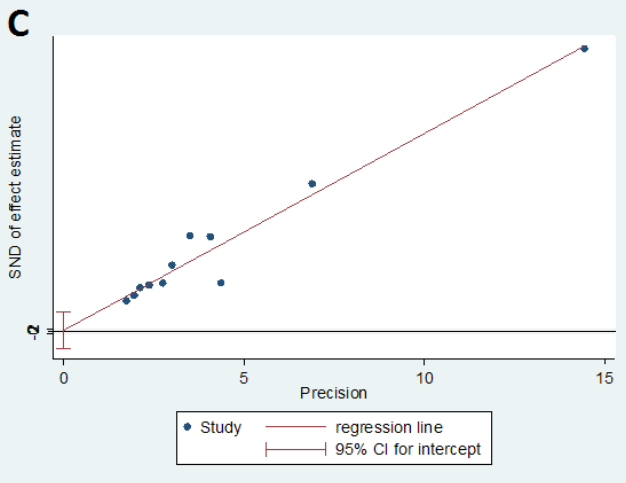

D

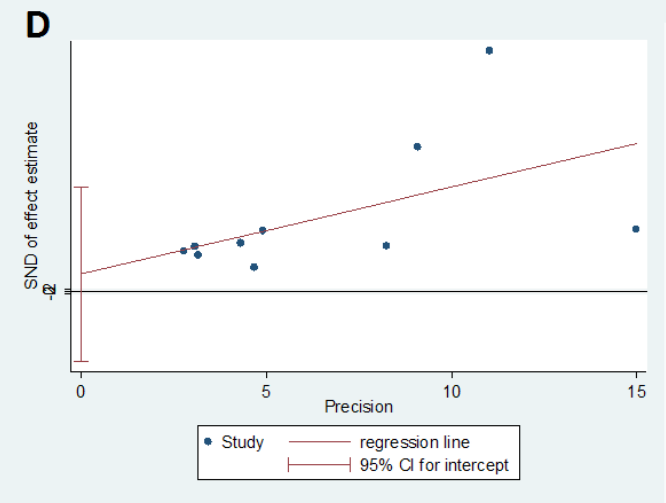

Figure 6. The Egger test for publication biasA: Vasomotor domain ( $P=0.198)$; B: Psychological domain $(P=0.907)$; C: Physical domain $(P=0.608)$; : Sexual domain $(P=0.659)$

study highlighted that the effects of ethnicity on menopausal symptoms are still questionable [37]. We also found that the mean score of QOL in the sexual domain was 6.71 1.77 (in the possible range of $0-18$ ), denoting high QOL. Two previous studies reported that the mean score of sexual QOL among postmenopausal women was $8.7 \pm 6.3$ [13] and $6.9 \pm 8.58$ [25]. Another study reported that the mean score of sexual QOL was $9.3 \pm 6.6$ in early menopause and $10.77 \pm 7.5$ in late menopause, denoting QOL reduction with age[15]. These contradictory results among the studies are due to differences in their samples, designs, and sociocultural contexts [38].Menopause-related hormonal changesprofoundly affect renal function and cause symptoms, which considerably affect QOL and sexuality. Therefore, sexual dysfunction is among the most common problems during menopausal transition and postmenopausal period. The most common sexual complaints among postmenopausal women are vaginal dryness, dyspareunia, and decreased libido. There- fore, regular sexual assessment should be performed for middle-aged and older women and they should be provided with the opportunity to verbalize their sexual problems. Such assessments can facilitate the early diagnosis and management of sexual dysfunction[39]. Study findings also showed that the total mean score of QOL among 3413 postmenopausal women was $57.89 \pm 12.8$ (in the possible range of 0-174), indicating good QOL. Several earlier studies in different countries also reported good QOL among postmenopausal women [40-42]. However, some studies reported low QOL among menopausal women[14, 43,44]. Menopause, aging, social deprivation, and affliction by chronic illnesses can negatively affect QOL amongmiddle-aged and older women. Some other studies found no significant relationship between menopause and QOL. For instance, a study with an eight-year follow-up period on 1165 Finnish women aged 45-64 found that menopause had no significant relationship with QOL [45]. A cross-sectional study in Spain and Majorca on 378 
postmenopausal women and fifty pre-menopausal women also found a weak relationship between menopause and QOL [46]. Another study in Hong Kongon women aged 40-59 years also showed no significant difference between premenopausal and postmenopausal QOL [19]. These contradictory results may be due to the fact that although menopausal symptoms may affect QOL of most women[36, 37], only a small number of them experiencethe sever effects of menopause [37]. Another justification for these contradictory results is the fact that women gradually learn how to manage and cope with menopausal symptoms. In other words, QOL in menopausal and postmenopausal periods is affected by women's ability to cope with menopausal symptoms and menopause-related changes in the body as well as their feelings of satisfaction and happiness in these periods. Studies have shown the positive effects of education about positive thinking, physical activity, and lifestyle modification on menopausal symptoms and QOL $[6,19]$. Therefore, educational interventions are recommended for QOL improvement among postmenopausal women.

\section{Study Limitations}

This study reviewed only cross-sectional studies and hence, provides no information about the effects of the normal process of aging on postmenopausal women' QOL. Moreover, at the time of the study, online scientific databases in Iran provided no option for combining search results using Boolean operators "AND" and "OR".

\section{Strengths}

This study reviewed studies that had used a valid and reliable MenQOL questionnaire.

\section{Conclusion}

This systematic review and meta-analysis show that Iranian postmenopausal women's QOL is higher than moderate. The lowest and the highest quality of life are related to the physical and sexual domains, respectively. Policymaking for public education, patient education, and healthcare staff education are recommended to facilitate QOL improvement among postmenopausal women.

\section{Conflict of Interest}

The authors declare that they have no conflict of interest.

\section{References}

1. Im EO, Lee B, Chee W, Dormire S, and Brown A, A national multiethnic online forum study on menopausal symptom experience.Nurs Res. 2010. 59(1). 26-33.

2. Park S, Yang MJ, Ha SN, and Lee JS, Effective Anti-aging Strategies in an Era of Super-aging.J Menopausal Med. 2014. 20(3). 85-9.

3. Ghazanfarpour M, Kaviani M, Abdolahian S, Bonakchi H, Najmabadi Khadijeh M, Naghavi M, et al., The relationship between women's attitude towards menopause and menopausal symptoms among postmenopausal women.Gynecol Endocrinol. 2015. 31(11). 860-5.

4. Ghazanfarpour M, Sadeghi R, Roudsari RL, Khorsand I, Khadivzadeh T, and Muoio B, Red clover for treatment of hot flashes and menopausal symptoms: A systematic review and meta-analysis.Journal of Obstetrics and
Gynaecology. 2016. 36(3). 301-311.

5. Sun N, Xing J, Li L, Han XY, Man J, Wang HY, et al., Impact of Menopause on Quality of Life in Community-based Women in China: 1 Year Follow-up.Arch Psychiatr Nurs. 2018. 32(2). 224-228.

6. Forouhari S, Khajehei M, Moattari M, MohitM, Rad MS, and Ghaem H, The Effect of Education and Awareness on the Qualityof-Life in Postmenopausal Women.Indian J Community Med. 2010. 35(1). 109-14.

7. Nikpour S and Haghani H, The effect of exercise on quality of life in postmenopausal women referred to the Bone densitometry centers of Iran University of Medical Sciences.J Midlife Health. 2014. 5(4). 176-9.

8. Kulasingam S, Moineddin R, Lewis JE, and Tierney MC, The validity of the Menopause Specific Quality of Life Questionnaire in older women.Maturitas. 2008. 60(3-4). 239- 
43.

9. Bouzari Zinatossadat, Javadian Kotenaie Maryam, Darzi Ali-Asghar, and Hajian Karimolah, Menopausal Symptoms Can Be Influenced by Various Sociodemographic Factors and Quality of Life (QoL) Decreases after the Menopause.World Appl. Sci. J. 2013. 23(9). 1221-1230.

10. Chiu YW, Moore RW, Hsu CE, Huang CT, Liu HW, and Chuang HY, Factors influencing women's quality of life in the later half of life.Climacteric. 2008. 11(3). 201-11.

11. Fallahzadeh H, Quality of life after the menopause in Iran: a population study.Qual Life Res. 2010. 19(6). 813-9.

12. Golian Tehrani S, Bazzazian S, Bakhtiarian A, and Ghobadzadeh M, Effects of calci soya balance and vitagnus on menopausal symptoms.Iran Red Crescent Med J. 2014. 16(10). e13651.

13. Williams RE, Levine KB, Kalilani L, Lewis J, and Clark RV, Menopause-specific questionnaire assessment in US populationbased study shows negative impact on healthrelated quality of life.Maturitas. 2009. 62(2). 153-9.

14. Abedzadeh M, Taebi M, SaberiF, and Sadat $Z$, Quality of life and related factors in Menopausal women in Kashan city.Iranian South Medical Journal. 2009. 12(1). 81-88.

15. Chen Y, Lin SQ, Wei Y, Gao HL, Wang SH, and $\mathrm{Wu}$ ZL, Impact of menopause on quality of life in community-based women in China. Menopause. 2008. 15(1). 144-9.

16. Ozkan S, Alatas ES, and Zencir M, Women's quality of life in the premenopausal and postmenopausal periods.Qual Life Res. 2005. 14(8). 1795-801.

17. Satoh T and Ohashi K, Quality-of-life assessment in community-dwelling, middleaged, healthy women in Japan.Climacteric. 2005. 8(2). 146-53.

18. Cheng MH, Lee SJ, Wang SJ, Wang PH, and Fuh JL, Does menopausal transition affect the quality of life? A longitudinal study of middle-aged women in Kinmen.Menopause. 2007. 14(5). 885-90.

19. Li S, Ho SC, and Sham A, Relationship between menopause status, attitude toward menopause, and quality of life in Chinese midlife women in Hong Kong.Menopause. 2016. 23(1). 67-73.

20. Vesco KK, Haney EM, Humphrey L, Fu R, and Nelson HD, Influence of menopause on mood: a systematic review of cohort studies. Climacteric. 2007. 10(6). 448-65.
21. Fallahzadeh H, Dehghani Tafti A, Dehghani Tafti M, Hoseini F, and Hoseini H, Factors Affecting Quality of Life after Menopause in Women, Yazd, 2008.Journal of Shahid Sadoughi University of Medical Sciences and Health Services. 2011. 18(6). 552-558.

22. Higgins JP, Thompson SG, Deeks JJ, and Altman DG, Measuring inconsistency in meta-analyses.Bmj. 2003. 327(7414). 55760.

23. Higgins J and Green S, Cochrane handbook for systematic reviews of interventions. 2011, New York City, New York, United States, Wiley Online Library.

24. Ghorbani R, Nassaji M, Shahbazi A, Rostami $\mathrm{B}$, and Taheri M, Association between quality of life, menopausal status, and sociodemographic factors among middleaged women in Iran.J Egypt Public Health Assoc. 2015. 90(4). 166-70.

25. Karmakar N, Majumdar S, Dasgupta A, and Das S, Quality of life among menopausal women: A community-based study in a rural area of West Bengal.J Midlife Health. 2017. 8(1). 21-27.

26. Barat S, Javadian Kotenaei M, Bouzari Z, Sam S, and Taheri Otaghsar SM, Factors affecting life process of postmenopausal women.Journal of Babol University of Medical Sciences. 2013. 15(3). 30-35.

27. Golmakany A, Shariati Sarcheshmeh M, MarouzI P, and Rezaie Sani T, Body Mass Index and its relation to menopausal women's quality of life.Journal of Holistic Nursing and Midwifery. 2014. 25(79). 48-55.

28. Monshipour S, Mokhtari Lakeh N, Rafat F, and Kazemnejad Leili F, Related factors to Menopausal women's quality of life in Rasht. Journal of Holistic Nursing and Midwifery. 2014. 25(79). 80-88.

29. Shobeiri F, Jenabi E, Hazavehei SM, and Roshanaei G, Quality of Life in Postmenopausal Women in Iran: A Population-based Study.J Menopausal Med. 2016. 22(1). 31-8.

30. Jeddi FR and Nabovati E, Features and Effects of Information Technology-Based Interventions to Improve Self-Management in Chronic Kidney Disease Patients: a Systematic Review of the Literature. 2017. 41(11). 170.

31. Bankowski BJ, Gallicchio LM, Whiteman MK, Lewis LM, Zacur HA, and Flaws JA, The association between menopausal symptoms and quality of life in midlife women.Fertil Steril. 2006. 86(4). 1006-8. 
32. Shepherd-Banigan M, Goldstein KM, Coeytaux RR, McDuffieJR, Goode AP, Kosinski AS, et al., Improving vasomotor symptoms; psychological symptoms; and health-related quality of life in peri- or post-menopausal women through yoga: An umbrella systematic review and metaanalysis.Complement Ther Med. 2017. 34. 156-164.

33. Shirvani M and Heidari M, Quality of Life in Postmenopausal Female Members and Non-members of the Elderly Support Association.J Menopausal Med. 2016. 22(3). 154-160.

34. Yousefi Z, Sharifi K, Tagharrobi Z, and Akbari H, The Effect of Narrative Reminiscence on Happiness of Elderly Women.Iran Red Crescent Med J. 2015. 17(11). e19612.

35. Matthews KA and Bromberger JT, Does the menopausal transition affect health-related quality of life? Am J Med. 2005. 118 Suppl 12B. 25-36.

36. Ceylan B and Ozerdogan N, Factors affecting age of onset of menopause and determination of quality of life in menopause.Turk J Obstet Gynecol. 2015. 12(1). 43-49.

37. Abdullah B, Moize B, Ismail BA, Zamri $M$, and Mohd Nasir NF, Prevalence of menopausal symptoms, its effect toquality of life among Malaysian women and their treatment seeking behaviour.Med J Malaysia. 2017. 72(2). 94-99.

38. Nappi RE and Lachowsky M, Menopause and sexuality: prevalence of symptoms and impact on quality of life.Maturitas. 2009. 63(2). 138-41.

39. Genazzani AR, Gambacciani M, and Simoncini T, Menopause and aging, quality of life and sexuality.Climacteric, 2007. 10(2). 88-96.

40. Aloumanis K, Karras D, Drossinos V, Korelis E, and Polydorakis A, Fracture Incidence, Quality of Life, and Back Pain during 18-Months Treatment with Teriparatide in Greek PostmenopausalWomen with Osteoporosis: Results fromthe European Forsteo Observational Study.Journal of Osteoporosis. 2011.

41. Oleksik A, Lips P, Dawson A, Minshall ME, Shen W, Cooper C, et al., Health-related quality of life in postmenopausal women with low BMD with or without prevalent vertebral fractures.J Bone Miner Res. 2000. 15(7). 1384-92.

42. Welton AJ, Vickers MR, Kim J, Ford D,
Lawton BA, MacLennan AH, et al., Health related quality of life after combined hormone replacement therapy: randomised controlled trial.Bmj. 2008. 337. a1190.

43. Chedraui P, San Miguel G, and Avila C, Quality of life impairment during the female menopausal transition is related to personal and partner factors.Gynecol Endocrinol. 2009. 25(2). 130-5.

44. Waidyasekera H, Wijewardena K, Lindmark G, and Naessen T, Menopausal symptoms and quality of life during the menopausal transition in Sri Lankan women.Menopause. 2009. 16(1). 164-70.

45. Moilanen JM, Aalto AM, Raitanen J, Hemminki E, Aro AR, and Luoto R, Physical activity and change in quality of life during menopause--an 8-year follow-up study. Health Qual Life Outcomes. 2012. 10. 8.

46. Calvo-Perez A and Campillo-Artero C, Quality of life of menopausal women in the island of Majorca: a population based study. Gynecol Endocrinol. 2013. 29(6). 556-8.

47. Abdi N and Solhi M, Quality of life in postmenopausal women in Tehran (quality of life).Health education and health promotion . 2014. 2(2). 87-96. \{In Persion\}

48. Daipoor S, Sayahi Y, Alavi A, Naghavi K, and Safari Moradabadi A, The application of the PRECEDE model to investigate the determinants of quality of life in postmenopausal women in Bandar Abbas, Iran.Scientific Journal of Hamadan Nursing \& Midwifery Faculty. 2015. 23(1). 84-93.

49. Ghazanfarpour M, Abdolahian S, Zare M, and Shahsavari S, Association between anthropometric indices and quality of life in menopausal women.Gynecol Endocrinol. 2013. 29(10). 917-20.

50. Makvandi S, Bastami A, Zargar Shoushtari S, Yazdizadeh H, Etemadpour Y, and Taghavifar S, Quality of Life and Its Related Factors in Postmenopausal Women Referred to Ahvaz East Health Center, Iran, 2012.The Iranian Journal of Obstetric, Gynecology and Infertility. 2013. 16(59). 6-13.

51. Mirhaghjou SN, Niknami M, Moridi M, Pakseresht S, and Kazemnejad E, Quality of life and its determinants in postmenopausal women: a population-based study.Appl Nurs Res. 2016. 30. 252-6.

52. Yazdi Z, Sadeghniiat-Haghighi K, Ziaee A, Elmizadeh K, and Ziaeeha M, Influence ofsleep disturbances on quality of life of Iranian menopausal women.Psychiatry J. 2013. 2013. 1-5. 